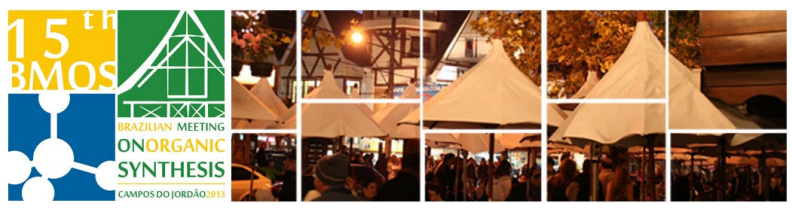

\title{
Phenanthridine derivatives via palladium catalyzed intramolecular functionalization of $\mathrm{C}\left(\mathrm{sp}^{2}\right)-\mathrm{H}$ bonds.
}

\author{
Roberta L. da Costa (PG)*, Simon J. Garden (PQ) \\ Instituto de Química, Universidade Federal do Rio de Janeiro, CT, Bloco A, \\ Cidade Universitária - Ilha do Fundão, 21949-900 - Rio de Janeiro - RJ \\ *robertarural@gmail.com or garden@iq.ufri.br
}

Keywords: C-H functionalization, biaryl bonds, palladium catalysis.

\section{INTRODUCTION}

The biaryl structural motif is found in many natural and synthetic products of which phenanthridine derivatives are a specific heterocyclic system. ${ }^{1}$

Biaryl bond formation is an important aspect in the synthesis of these compounds. As a result, organic chemists have sought to develop new and more efficient biaryl bond forming methods such as $\mathrm{C}-\mathrm{H}$ direct arylation. ${ }^{2}$

\section{RESULTS AND DISCUSSION}

In developing upon our original methodology (M1), ${ }^{3}$ and that of others (M2), ${ }^{4}$ we have discovered a more robust method (M3) for the intramolecular C$\mathrm{H}$ functionalization of $\mathrm{N}$-alkyl- and $\mathrm{N}$-aroyl- anilines to give phenanthridine derivatives (Figures 1 and 2).

Methodologies tested for biaryl bond formation. All methods: Substrate $(1 \mathrm{mmol}), \mathrm{DMF}(5 \mathrm{~mL})$ and stirring at $120^{\circ} \mathrm{C}$. M1 $-10 \mathrm{~mol} \% \mathrm{Pd}(\mathrm{OAc})_{2}, \quad \mathrm{Bu}_{4} \mathrm{NBr}$ (1.1 mmol), KOAc $(5 \mathrm{mmol}) . \mathbf{M} 2-5 \mathrm{~mol} \% \mathrm{Pd}(\mathrm{OAc})_{2}$, $5 \mathrm{~mol} \%$ dppe, $\mathrm{K}_{2} \mathrm{CO}_{3}(5 \mathrm{mmol})$ an argon atmosphere. M3 - $5 \mathrm{~mol} \% \mathrm{Pd}(\mathrm{OAc})_{2}, 5 \mathrm{~mol} \%$ dppe, $5 \mathrm{~mol} \%$ hydroquinone $(\mathrm{HQ}), \mathrm{Bu}_{4} \mathrm{NBr}(1.1 \mathrm{mmol})$, $\mathrm{KOAc}(5 \mathrm{mmol})$, an argon atmosphere.

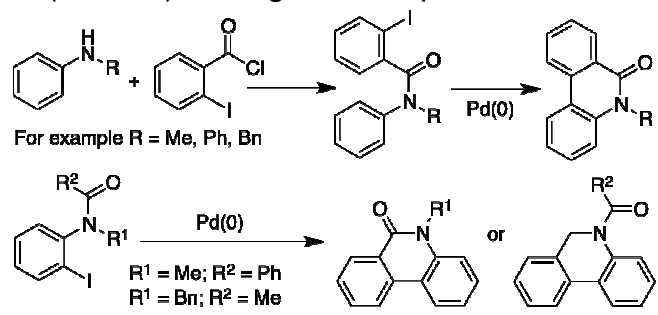

Figure 1. Biaryl bond formation in the preparation of phenanthridine derivatives via $\mathrm{C}-\mathrm{H}$ functionalization.

Substrates for investigation of the $\mathrm{C}-\mathrm{H}$ functionalization reaction were prepared by the acylation of appropriately functionlized aniline derivatives. Reaction methods M2 and M3 (absence of $H Q$ ) were found to have long induction periods when virgin glass vials and stirrer bars were used and gave principally products resulting from reduction of the $\mathrm{C}-\mathrm{I}$ bond. However, the addition of $\mathrm{HQ}$ in M3 resulted in "instaneous" reactions to give the desired products. HQ had no effect upon M2. However, M2 gave results comprable to $\mathbf{M} 3$ when using glassware previously used for palladium catalyzed reactions. All products were spectroscopically characterized.

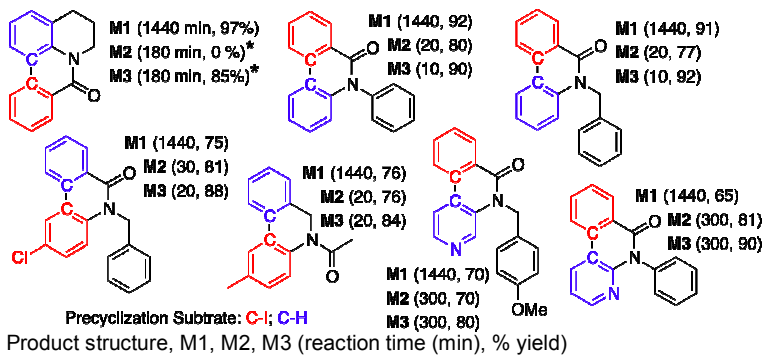

Figure 2. Illustrative results for catalytic intramolecular C$\mathrm{H}$ functionalization. * The reaction times for M2 and M3 were determined by GC-MS analysis of reaction aliquotes. * In the case of M2 no cyclized product was formed and substrate was consumed due to reduction of the $\mathrm{C}-\mathrm{I}$ bond.

\section{CONCLUSION}

The palladium catalyzed functionalization of a C$\mathrm{H}$ bond allowed the satisfactory synthesis of phenanthridine derivatives. M3 was found to be as good as or better than M2 and both methods are a phenomenal advance upon our original method M1. Reaction times have been reduced from 12-24 hours to 10-300 minutes and catalyst loading has been halfed, the overall result being similar or better product yields.

\section{ACKNOWLEDGEMENTS}

CAPES, CNPQ, FAPERJ and PGQU-IQ-UFRJ

\section{REFERENCES}

${ }^{1}$ Ishida, J., Hattori, K., Yamamoto, H., Iwashita, A., Mihara, K., Matsuoka, N., Bioorg. Med. Chem. Lett. 2005, 15, 4221. b) Pearson, R., Zhang, S., He, G., Edwards, N., Chen, G. Beilstein J. Org. Chem. 2013, 9, 891.

2 a) Yeung, C.S., Dong, V.M. Chem. Rev. 2011, 111, 1215. b) Alberico, D., Scott, M.E., Lautens, M. Chem. Rev. 2007, 107, 174. c) Yamaguchi, J., Yamaguchi, A.D., Itami, K. Angew. Chem. Int. Ed. 2012, 51, 8960.

${ }^{3}$ Torres, J.C.; Pinto, A.C.; Garden, S.J. Tetrahedron, 2004, 60, 9889.

${ }^{4}$ Bernini, R.; Cacchi, S.; Fabrizi, G.; Sferrazza, A.; Synthesis, 2008, 729 . 